\title{
Host Range of Plasmodiophora brassicae on Cruciferous Crops and Weeds in China
}

Li Ren, Li Xu, Fan Liu, Kunrong Chen, Chaochao Sun, Jun Li, and Xiaoping Fang, Oil Crops Research Institute of the Chinese Academy of Agricultural Sciences, Key Laboratory of Biology and Genetic Improvement of Oil Crops, Ministry of Agriculture, Wuhan 430062, China

\begin{abstract}
Ren, L., Xu, L., Liu, F., Chen, K., Sun, C., Li, J., and Fang, X. 2016. Host range of Plasmodiophora brassicae on cruciferous crops and weeds in China. Plant Dis. 100:933-939.

Clubroot caused by Plasmodiophora brassicae is an increasingly important soilborne disease in China. The host range of P. brassicae was investigated with 30 cruciferous plants, including 16 crop species, 9 ornamentals, and 5 weeds in field and pot-cultured conditions. In the field, 17 species from five genera produced visible galls, and these included radish, Capsella bursa-pastoris, Orychophragmus violaceus, Sinapis alba, and 13 Brassica crops. In pot-cultured conditions, an additional 13 plant species (11 genera) were determined to be hosts of $P$. brassicae. Five common weeds were found to be hosts of $P$. brassicae, including C. bursa-pastoris, Lepidium apetalum, Descurainia sophia, $S$. alba, and Thellungiella salsuginea. The infection of these plants

was confirmed via polymerase chain reaction (PCR) with primers specific to $P$. brassicae. No galls were found on Matthiola incana roots in the field or in pots and no resting spores of $P$. brassicae were observed in $M$. incana roots, although $P$. brassicae was detected in $M$. incana roots via PCR. Microscopic examination revealed infection only in the root hairs of $M$. incana roots. These results suggested that $M$. incana was highly resistant to $P$. brassicae in China and could be developed as a bait crop. In total, 297 accessions of oilseed rape were tested in the field, and 3 accessions of Brassica napus and 1 accession of B. juncea were found to be highly resistant to clubroot disease. These resistant resources provide options for managing clubroot in P. brassicae-infested fields.
\end{abstract}

Clubroot of cruciferous plants caused by Plasmodiophora brassicae is an economically important soilborne disease. The disease has been reported in more than 60 countries and can result in total yield loss in heavily infested fields (Dixon 2009; Hwang et al. 2012). In China, clubroot is distributed throughout the country and causes an average yield loss of 20 to $30 \%$ (Chai et al. 2014; Wang et al. 2011). Chinese cabbage (Brassica rapa pekinensis) and oilseed rape (B. napus) are the most common cruciferous crops in China and clubroot is a major constraint in production of these crops.

Knowledge regarding clubroot hosts in China is fragmentary. Theoretically, all species of the family Brassicaceae are potential hosts for P. brassicae. Karling (1968) described more than 300 clubroot hosts; however, isolates of the pathogen have different capacities to infect specific host genotypes (Honig 1931). Few infection studies have been performed outside the genera Brassica, Raphanus, and Arabidopsis (Dixon 2009; Howard et al. 2010). To the best of our knowledge, natural infections were reported in genera Brassica, Raphanus, Arabidopsis, Eruca (Paz Lima et al. 2004), Capsella (Kim et al. 2011), Cardamine (Tanaka et al. 1993), Matthiola (Liu 2012), and Isatis (Xiong et al. 2012); among these, Brassica, Raphanus (Zhang and Zhao 2012), Isatis, Matthiola, and Capsella (Ren et al. 2014) were reported in China. Some noncruciferous plants are also listed as hosts of P. brassicae, including nasturtium (Tropaeolum majus), papaya (Carica papaya), corn poppy (Papaver rhoeas), and clover (Trifolium repens) (Ludwig-Müller et al. 1999). The root hair (primary) infection in these species was observed with artificial inoculation under ideal environmental conditions.

Cruciferous weeds may play a role in clubroot epidemics because the disease has been reported in at least five species of cruciferous

Corresponding author: X. Fang; E-mail: xpfang2008@163.com

This research was supported by a grant from the Natural Science Foundation of China grants $(31401720,31501617$ and 31101124$)$ and by the Special Fund for the Agro-scientific Research in the Public Interest (201003029).

Accepted for publication 20 November 2015.

http://dx.doi.org/10.1094/PDIS-09-15-1082-RE

(C) 2016 The American Phytopathological Society weeds (Kim et al. 2011; Ren et al. 2014; Tanaka et al. 1993). In Japan, clubroot on the cruciferous weed Cardamine flexuosa was distributed in 43 prefectures. Thus, this plant was considered to be the most suitable plant species to investigate the distribution of clubroot (Tanaka et al. 2006). In Britain, Buczacki and Ockendon (1979) observed clubroot infection on several common cruciferous weeds under controlled conditions, including wild cabbage (Brassica oleracea), shepherd's purse (Capsella bursa-pastoris), wall rocket (Diplotaxis muralis), treacle mustard (Erysimum cheiranthoides), white mustard (Sinapis alba), charlock (S. arvensis), hedge mustard (Sisymbrium officinale), and field penny cress (Thlaspi arvense). However, few studies have been conducted on the susceptibility of weeds to clubroot in China.

C. bursa-pastoris, Sinapis alba, herb sophia (Descurainia sophia), and pepperweed (Lepidium apetalum) are widespread cruciferous weeds in China. Saltwater cress (Thellungiella salsuginea) is also a common weed in saline fields in northern China. Knowledge of the susceptibility of these weeds to Plasmodiophora brassicae is limited but extremely important for management of clubroot cultivated on cruciferous crops.

In this article, a field survey of natural infection and assays in potcultured plants were conducted to gain a better understanding of the host range of $P$. brassicae in China.

\section{Materials and Methods}

Pathogen isolates and plant species. $P$. brassicae isolates collected from field-grown oilseed rape plants in Hubei and Sichuan Provinces, previously determined to be pathotype 4 based on the Williams system ( $\mathrm{Ji}$ et al. 2013), were used in this study. The cruciferous plants used in this study are listed in Tables 1 and 2 . In total, 30 species in 17 genera were tested. The selected genotypes of crops and ornamentals were obtained from Oil Crops Research Institute of the Chinese Academy of Agricultural Sciences or purchased from commercial seed companies. Seed of cruciferous weeds were collected from plants in agricultural fields or roadside verges (Table 1); seed of $C$. bursa-pastoris were collected in fields planted with oilseed rape or Chinese cabbage in which crops showed clubroot symptoms. Seed were stored in sealed bags at $4{ }^{\circ} \mathrm{C}$ and surface disinfected with $5 \%$ sodium hypochlorite for $5 \mathrm{~min}$ before use.

Field surveys. Field surveys for clubroot diseases of cruciferous plants were conducted in 13 provinces from the northeast (Heilongjiang Province) to the southwest (Yunnan Province) of China from 
2010 to 2014. The investigation was conducted based on visible galls on roots. Additionally, susceptibility of selected plants (Tables 1 and 2 ) to $P$. brassicae was tested in fields with a history of clubroot. Seed were directly sown in P. brassicae-infested fields in Hubei Province. The experiment was established as a randomized complete block design with two replications. The plot size was 2 by $1.2 \mathrm{~m}$ (four rows) with 100 seedlings. After 2 months, the plants were uprooted and examined for gall formation, and disease incidence and disease index (DI) were calculated. Root symptoms were evaluated on a 0-to-3 scale and DI was calculated as previously described (Kuginuki et al. 1999; Xue et al. 2008), where $0=$ no galls, $1=$ a few small galls on less than one-third of the roots, $2=$ moderate galling (small to medium galls on one-third to two-thirds of the roots), and $3=$ severe galling (medium to large galls on more than two-thirds of the roots). Results are expressed as means of two replicates.
Pot trials. Root galls $(50 \mathrm{~g})$ collected from fields were homogenized in a household blender (HR2003; Philips Electronics Hong Kong Ltd.) with $200 \mathrm{ml}$ of distilled water. The slurry was filtered through eight layers of cheesecloth and the filtrate was centrifuged at $2,000 \times g$ for $5 \mathrm{~min}\left(4^{\circ} \mathrm{C}\right)$. The pellets were suspended in $200 \mathrm{ml}$ of distilled water, and the resting spore concentration was quantified using a hemocytometer under a microscope. The $\mathrm{pH}$ of the spore suspension was adjusted to 6.0 with $5 \%$ nitric acid. The freshly prepared resting spore suspension was used for inoculation. The inocula were mixed with a sterilized soil matrix (vermiculite and peat soil at 3:1 ratio) in plastic pots to a final concentration of $1 \times 10^{7}$ spores/g of soil. Soil treated with the same volume of sterile water was used as a control. Seed of each plant species were pregerminated on moist filter paper for 2 to 5 days $\left(20^{\circ} \mathrm{C}\right)$ and then seeded into the pots, with 6 seeds/pot and five pots for each plant species.

Table 1. Cruciferous plants surveyed or tested in pots for susceptibility to clubroot

\begin{tabular}{|c|c|c|c|c|c|c|}
\hline \multirow[b]{2}{*}{ Common name } & \multirow[b]{2}{*}{ Botanical name } & \multirow[b]{2}{*}{$N^{\mathbf{b}}$} & \multirow[b]{2}{*}{ Source } & \multicolumn{3}{|c|}{ Clubroot $^{\mathbf{a}}$} \\
\hline & & & & Field & Pot & PCR \\
\hline Oilseed rape & Brassica napus & $>10$ & Hubei & + & + & + \\
\hline Chinese cabbage & B. rapa pekinensis & 3 & Jingyan Yinong, Beijing & + & + & + \\
\hline Brown mustard & B. juncea & $>10$ & Hubei & + & + & + \\
\hline Chinese kale & B. alboglabra & 3 & LuHeng Seeds, Beijing & + & + & + \\
\hline Cabbage & B. oleracea & 6 & LuHeng Seeds, Beijing & + & + & + \\
\hline Kale & B. oleracea var. acephala & 1 & Bejo Seeds, The Netherlands & + & + & + \\
\hline Radish & Raphanus sativus & 8 & Syngenta and Tézier & + & + & + \\
\hline Kohlrabi & B. oleracea var. gongylodes & 2 & Dayu Seeds, Hebei & + & ND & ND \\
\hline Tuber mustard & B. juncea var. tumida & 2 & Chengdu, Sichuan & + & ND & ND \\
\hline Sprouting broccoli & B. oleracea var. italica & 2 & Xinye, Henan & + & ND & ND \\
\hline Watercress & Nasturtium officinale & 1 & Luhe Seeds, Jinan, Shandong & ND & + & + \\
\hline Arugula & Eruca sativa & 1 & Lujinlan Seeds, Beijing & ND & + & + \\
\hline Woad & Isatis tinctoria & 2 & Yunnan & ND & + & + \\
\hline Sweet alyssum & Lobularia maritima & 2 & Takii Seed, Kyoto, Japan & ND & + & + \\
\hline English wallflower & Cheiranthus cheiri & 1 & Takii Seed, Kyoto, Japan & ND & + & + \\
\hline Siberian wallflower & C. allionii & 1 & Guomei Horticulture Co., Ltd., Zhejiang & ND & + & + \\
\hline Wallflower & C. maritimus & 1 & Guomei Horticulture Co., Ltd., Zhejiang & ND & + & + \\
\hline Dames rocket & Hesperis matronalis & 1 & Guomei Horticulture Co., Ltd., Zhejiang & ND & + & + \\
\hline Globe candytuft & Iberis umbellata & 1 & Takii Seed, Kyoto, Japan & ND & + & + \\
\hline Violet orychophragmus & Orychophragmus violaceus & 2 & Guomei Horticulture Co., Ltd., Zhejiang & + & + & + \\
\hline Virginia stock & Malcolmia maritime & 1 & Qinghai & - & + & + \\
\hline Stock & Matthiola incana & 8 & Xinnongfeng Seed and PanAmerican Seed & - & - & + \\
\hline White mustard & Sinapis alba & 3 & Qinghai & + & + & + \\
\hline Shepherd's purse & Capsella bursa-pastoris & 3 & Sichuan & + & + & + \\
\hline Herb sophia & Descurainia sophia & 1 & Qinghai & - & + & + \\
\hline Pepperweed & Lepidium apetalum & 1 & Qinghai & - & + & + \\
\hline Saltwater cress & Thellungiella salsuginea & 1 & Qinghai & - & + & + \\
\hline
\end{tabular}

a Symbols: $+=$ visible clubs on the roots or specific fragment present via polymerase chain reaction $(\mathrm{PCR}),-=$ no visible clubs on the roots, and $\mathrm{ND}=$ not determined.

${ }^{b}$ Number of varieties.

Table 2. Disease incidences and disease indices (DI) of clubroot on different species of Brassica in the field ${ }^{\mathrm{a}}$

\begin{tabular}{|c|c|c|c|c|c|c|c|c|c|}
\hline \multicolumn{2}{|r|}{ Species } & \multirow[b]{2}{*}{$N^{\mathrm{c}}$} & \multicolumn{2}{|c|}{ Disease incidence (\%) } & \multicolumn{2}{|c|}{ DI } & \multicolumn{3}{|c|}{ DI ranges $(N)^{\mathbf{b}}$} \\
\hline Common name & Botanical name & & Range & Average & Range & Average & $<30$ & 30-50 & $>50$ \\
\hline \multirow[t]{3}{*}{ Oilseed rape } & Brassica napus & 100 & $26.1-100$ & 81.9 & $20.3-96.3$ & 61.2 & 3 & 24 & 63 \\
\hline & B. rapa & 100 & $52.8-100$ & 81.0 & $40.5-96.5$ & 64.4 & 0 & 19 & 81 \\
\hline & B. juncea & 97 & $45.5-100$ & 85.1 & $25.8-100$ & 71.5 & 1 & 10 & 86 \\
\hline Turnip & B. rapa var. rapa & 2 & $83.8-88.0$ & 85.9 & $59.5-85.7$ & 68.2 & $\ldots$ & $\ldots$ & $\ldots$ \\
\hline Flowering stalk & B. rapa ssp. Chinensis var. utiliz & 2 & $39.6-77.3$ & 58.5 & $44.7-72.7$ & 54.0 & $\ldots$ & $\ldots$ & $\ldots$ \\
\hline Chinese kale & B. alboglabra & 2 & $55.0-56.5$ & 55.8 & $36.2-41.7$ & 39.9 & $\ldots$ & $\ldots$ & $\ldots$ \\
\hline Tuber mustard & B. juncea var. tumida & 2 & $39.3-66.7$ & 53.0 & $27.8-55.6$ & 37.0 & $\ldots$ & $\ldots$ & $\ldots$ \\
\hline Potherb mustard & B. juncea var. crispifolia & 2 & $23.6-58.3$ & 41.0 & $16.7-38.9$ & 24.1 & $\ldots$ & $\cdots$ & $\ldots$ \\
\hline Sprouting broccoli & B. oleracea var. italica & 2 & $28.0-47.1$ & 37.5 & $22.7-23.5$ & 22.9 & $\ldots$ & $\ldots$ & $\ldots$ \\
\hline Kohlrabi & B. oleracea var. gongylodes & 2 & $9.1-38.1$ & 23.6 & $6.1-28.6$ & 13.6 & $\cdots$ & $\ldots$ & $\ldots$ \\
\hline
\end{tabular}

a Trials were laid out in a randomized complete block design with two replications. Results were means of two experiments.

b Number of accessions with DI ranges shown.

c Number of accessions. 
To ensure the reliability of the results, one seed of Chinese cabbage 'Beijing New No. 3', highly susceptible to P. brassicae, was also sown in two of the five pots for each species. The pots were then placed in a chamber at 15 to $25^{\circ} \mathrm{C}$ under daily cycles of $14 \mathrm{~h}$ of light and $10 \mathrm{~h}$ of darkness and watered weekly with Hoagland nutrient solution (Luo et al. 2014) adjusted to pH 6.0. Four weeks after planting, plants in each pot were harvested to assess disease incidence and DI. Plants of stock (Matthiola incana), D. sophia, and L. apetalum were incubated for more than 2 months until flowering or podding. The roots of each plant were washed for 3 min under tap water for rating clubroot and for detecting $P$. brassicae with polymerase chain reaction (PCR). Pot trials were independently performed three times and results were expressed as means of three experiments.

PCR amplification. Because primary infection by $P$. brassicae caused no visible symptoms on plants, PCR was performed to confirm infection. One plant of each variety was randomly selected for extraction of genomic DNA using a cetyltrimethylammonium bromide protocol (Feng et al. 2013). PCR amplifications were conducted with primers Zgzb3-F (5'-GTATGGTAACAACGGACAAGGA-3') and Zgzb3-R (5'-AACGAACAGAAACCGACACTC-3'), which have been successfully used to characterize $P$. brassicae (Ren et al. 2012). All amplifications were conducted in a $25-\mu 1$ volume containing $2.5 \mu \mathrm{l}$ of $10 \times$ PCR buffer, $2.0 \mu \mathrm{l}$ of $2.5 \mathrm{mM}$ dNTP, $0.5 \mu \mathrm{l}$ of each forward and reverse primer, $1.0 \mu \mathrm{l}(1 \mathrm{U})$ of Taq DNA polymerase (Takara Co.), and $1.0 \mu \mathrm{l}$ (50 ng) of DNA from roots. A negative control consisting of DNA template of each plant species from noninfested soils was included in each PCR assay to ensure that the primers were $P$. brassicae specific. The amplification program consisted of an initial heat denaturation step at $94^{\circ} \mathrm{C}$ for $5 \mathrm{~min}$; followed by 35 cycles of $94^{\circ} \mathrm{C}$ for $30 \mathrm{~s}, 55^{\circ} \mathrm{C}$ for $30 \mathrm{~s}$, and $72^{\circ} \mathrm{C}$ for $1 \mathrm{~min}$; and a final extension at $72^{\circ} \mathrm{C}$ for $10 \mathrm{~min}$. The PCR products $(5 \mu \mathrm{l})$ were analyzed on a $1 \%$ agarose gel in Tris-acetate-EDTA buffer, stained with ethidium bromide, and visualized on a Gel Imaging System (G:BOX XL1.4; Syngene, USA).

Infection of $\boldsymbol{M}$. incana by $\boldsymbol{P}$. brassicae. In preliminary studies, no galls were observed on the roots of $M$. incana in the field or the greenhouse. To determine whether $P$. brassicae structures were present in $M$. incana, roots were harvested to observe root hairs via microscopy and resting spores in cells via scanning electron microscopy (SEM) and for further PCR evaluation. One M. incana variety ('Vintage Mix'; PanAmerican Seed) was selected, and the seed were pregerminated on wet filter paper at $20^{\circ} \mathrm{C}$ for 5 days, transferred to P. brassicae-infected Hoagland solutions (Luo et al. 2014), and incubated in a plant incubator for 45 days. At least 30 plants were incubated in liquid. Fresh nutrient solutions (pH 6.0) were added to the tubes as required. Four or five $M$. incana plants were harvested at 2, 3, 5, and 7 days after inoculation (dai) and rinsed with tap water. Roots of three plants were cut from the hypocotyl and stained with Phloxine B to facilitate observation under microscopy (Donald and Porter 2004). The infected root hairs were counted to calculate the infection rate. One (for 5 and 7 dai) or two (for 2 and 3 dai) plants were used for DNA isolation. DNA from the galled roots of Chinese cabbage was used as a positive control in PCR, and DNA from $M$. incana incubated for 7 days in noninfected solution was used as a negative control. Meanwhile, to ensure that the spores of P. brassicae that adhered to the roots had been washed off under the tap water, an $M$. incana plant from $P$. brassicae-free solution was harvested and immersed in a resting spore suspension for $10 \mathrm{~min}$ and rinsed for DNA isolation. This specimen was labeled as a rinsed control.

SEM. Infected and noninfected roots of 45-day-old M. incana seedlings were harvested and washed with sterile distilled water. Meanwhile, galls of Chinese cabbage and globe candytuft (Iberis umbellata) were also harvested as positive controls for SEM. Sections measuring 1 to $2 \mathrm{~mm}$ were cut and fixed in $2.5 \%$ glutaraldehyde $\left(4^{\circ} \mathrm{C}, 4 \mathrm{~h}\right)$ and $1 \%$ osmium tetroxide $\left(4^{\circ} \mathrm{C}, 2 \mathrm{~h}\right)$ in turn. The sections were dehydrated; rinsed with alcohol at successive concentrations of 50, 70, 80, 90, and 100\%; and subsequently dried with a Hitachi HCP-2 critical-point dryer. The slice was then placed on the sample stage and sputtered for 5 min with gold using a Hitachi E102 ion sputter. Examinations were performed with a Hitachi SU8010 scanning electron microscope from the Wuhan Institute of Virology, Chinese Academy of Sciences.

Statistical analysis. Analysis of variance (SAS version 8.01; SAS Institute Inc.) was used to analyze the disease incidences and DI of each variety and root infection rates of $M$. incana and Chinese cabbage. The percentage data were arcsine transformed to ensure homogeneity of variance prior to analysis. Means separation was conducted based on Fisher's least significant difference test at $P=0.05$.

\section{Results}

Natural infection. During 2010 to 2014, more than 200 fields in 13 provinces (municipalities) were surveyed for clubroot. The disease was observed on radish (Raphanus sativus), C. bursa-pastoris, and six Brassica spp., including oilseed rape, cabbage (B. oleracea), Chinese cabbage, flowering stalk (B. rapa subsp. chinensis var. utiliz), tuber mustard (B. juncea var. tumida), and sprouting broccoli (B. oleracea var. italica). Clubroot of the common weed $C$. bursapastoris was observed in Sichuan Province in a field in which rapeseed was heavily infected with $P$. brassicae. The disease was observed in all of the 13 provinces (municipalities) investigated, including Heilongjiang, Jilin, Liaoning, Shandong, Anhui, Henan, Shannxi, Hubei, Hunan, Chongqing, Sichuan, Yunan, and Guizhou. Disease incidence for these plants ranged from 6.2 to $100 \%$.

Seven species of Brassica were found to be hosts of clubroot in replicated field trials, including brown mustard ( $B$. juncea), field mustard (B. rapa), potherb mustard (B. juncea var. crispifolia), turnip (B. rapa var. rapa), kale (B. oleracea var. acephala), Chinese kale (B. alboglabra), and kohlrabi (B. oleracea var. gongylodes). Characteristic galls were also observed on the roots of $S$. alba and violet orychophragmus (Orychophragmus violaceus). PCR with P. brassicaespecific primers yielded the expected DNA fragment of $576 \mathrm{bp}$. The sequence was identical to the published sequence of $P$. brassciae, confirming the presence of the pathogen in these plants. No amplicons were for negative controls with symptomless plant DNA as templates.

Susceptibility of Brassica spp. All species of Brassica were infected by $P$. brassicae with different disease incidences and DI, and most were highly susceptible to clubroot (Table 2). Potherb mustard, sprouting broccoli, and kohlrabi were more resistant to clubroot than turnip.

Three types of oilseed rape (B. juncea, B. napus, and B. rapa) also showed different levels of susceptibility to clubroot. Approximately 100 accessions of each type of oilseed rape were directly sown in the field using a random complete block design with two replicates. Various levels of resistance to P. brassicae were observed among 297 genotypes of oilseed rape in the field. $B$. juncea was the most susceptible to clubroot and B. napus was the most resistant (Table 2). More resistant genotypes (with DI < 50) were found in B. napus, in which $24 \%$ of the accessions had DI of 30 to 50. In particular, accessions Y031, Y059, and Y178 were highly resistant with DI $<30$. No highly resistant (HR) genotypes (DI < 30) were identified in B. rapa and only one HR genotype (AY122) was found in B. juncea.

Pot trials. In all, 24 species were selected to investigate the host range of clubroot under pot-cultured conditions. In addition to the hosts confirmed in field trials, 13 species from 11 genera showed typical galls symptoms in $P$. brassicae-infested soils, including watercress (Nasturtium officinale), arugula (Eruca sativa), sweet alyssum (Lobularia maritima), English wallflower (Cheiranthus cheiri), Siberian wallflower (C. allionii), wallflower (C. maritimus), dames rocket (Hesperis matronalis), I. umbellate, woad (Isatis tinctoria), and four weed species (Table 1). Most plants were highly susceptible to clubroot and formed obvious and large galls on their roots, with the exception of kale and $N$. officinale, which showed slight root hypertrophy.

Infection of cruciferous weeds by $\boldsymbol{P}$. brassicae. Five common weeds, including $T$. salsuginea, S. alba, Capsella bursa-pastoris, Lepidium apetalum, and D. sophia, were tested for their susceptibility to clubroot in the field and in pots. In every test, the susceptible Chinese cabbage Beijing New No. 3 showed 100\% disease 
incidence, thereby demonstrating the suitable conditions in the pot trials for clubroot development.

All five weed species produced macroscopic galls on the main roots in inoculated pots. The galls on the weed roots were much smaller than those on the Chinese cabbage roots. The weed roots were small and thin and the galls were correspondingly small. $T$. salsuginea and $S$. alba exhibited the greatest clubroot incidences among the tested weeds, with an incidence of $100 \%$. D. sophia exhibited the lowest incidence of $33.3 \%$. The disease was less severe in the field than in the pots and the difference was significant $(P=0.01)$ for all tested weeds. For example, the roots of L. apetalum and D. sophia did not develop visible galls in the field, whereas the clubroot incidence ratings in pots were $84.6 \%$ for L. apetalum and $33.3 \%$ for D. sophia. For the inoculated S. alba and C. bursa-pastoris, the clubroot incidence ratings in pots were 100 and $62.5 \%$, respectively, whereas the incidence ratings in field conditions were 72.2 and $6.2 \%$, respectively.
Infection of $M$. incana by $\boldsymbol{P}$. brassicae. In both the pot and field tests, the roots of $M$. incana inoculated with $P$. brassicae showed root reductions. However, no hypertrophy was observed, despite the fact that the indicator plant, Chinese cabbage, formed galls in the same pot that was planted with M. incana (Fig. 1A). SEM studies of infected Chinese cabbage roots revealed the presence of resting spores of $P$. brassicae, which were distributed throughout the host tissues (Fig. 1B). The spores were nearly circular, with spikes on the surfaces; the average spore diameter was $2.9 \mu \mathrm{m}$ (range 2.7 to 3.2). Resting spores resembling those found in Chinese cabbage roots were also observed in the roots of Iberis umbellate (Fig. 1C); however, no spores were found in the roots of $M$. incana collected from the soil infested with $P$. brassicae (Fig. 1E).

Despite this, a 576-bp PCR amplicon was obtained from the DNA of $M$. incana roots. No fragment was obtained from the DNA of noninfected $M$. incana roots, suggesting that the amplified DNA band was from $P$. brassicae. No fragment was detected from DNA of

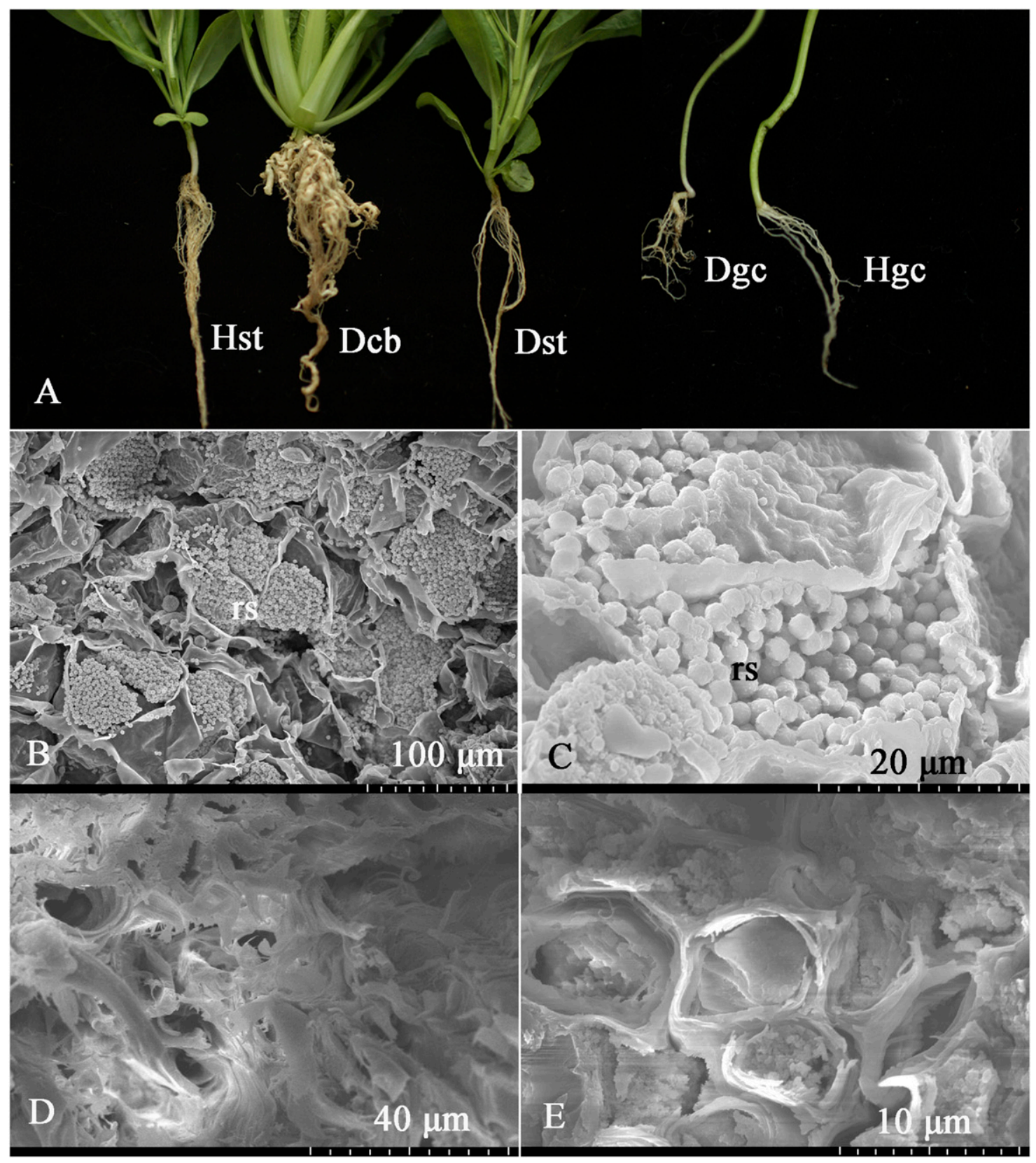

Fig. 1. Phenotypes of Matthiola incana, Chinese cabbage, and globe candytuft (Iberis umbellata) after infection with Plasmodiophora brassicae for 45 days and scanning electron micrographs of roots. A, Phenotypes of healthy M. incana from P. brassicae-free soils (Hst), diseased Chinese cabbage from P. brassicae-infected soils (Dcb), diseased M. incana (Dst), diseased Iberis umbellata (Dgc), and healthy I. umbellata (Hgc). B, Resting spores (rs) distributed throughout the root of Chinese cabbage after growth in $P$. brassicaeinfested soil. C, Resting spores in the roots of $I$. umbellate after growth in $P$. brassicae-infested soil. D, Root of M. incana from sterile soil. E, No resting spores present in root of $M$. incana grown in $P$. brassicae-infested soil. 
the rinsed control, which demonstrated that rinsing was effective for removing resting spores from root surfaces. Thus, the PCR band was not from resting spores adhering to the root surface. To confirm that the $M$. incana roots were infected by $P$. brassicae, a solution culture method was used to observe root hair infection. P. brassicae was detected via PCR in both Chinese cabbage and $M$. incana as early as 2 dai (Fig. 2F). Root hair observation via microscopy indicated that no apparent pathogen structures were observed in the root hairs at 2 and 3 dai in the $M$. incana roots. Primary plasmodia were first observed in a few root hairs of the $M$. incana at 5 dai, which was
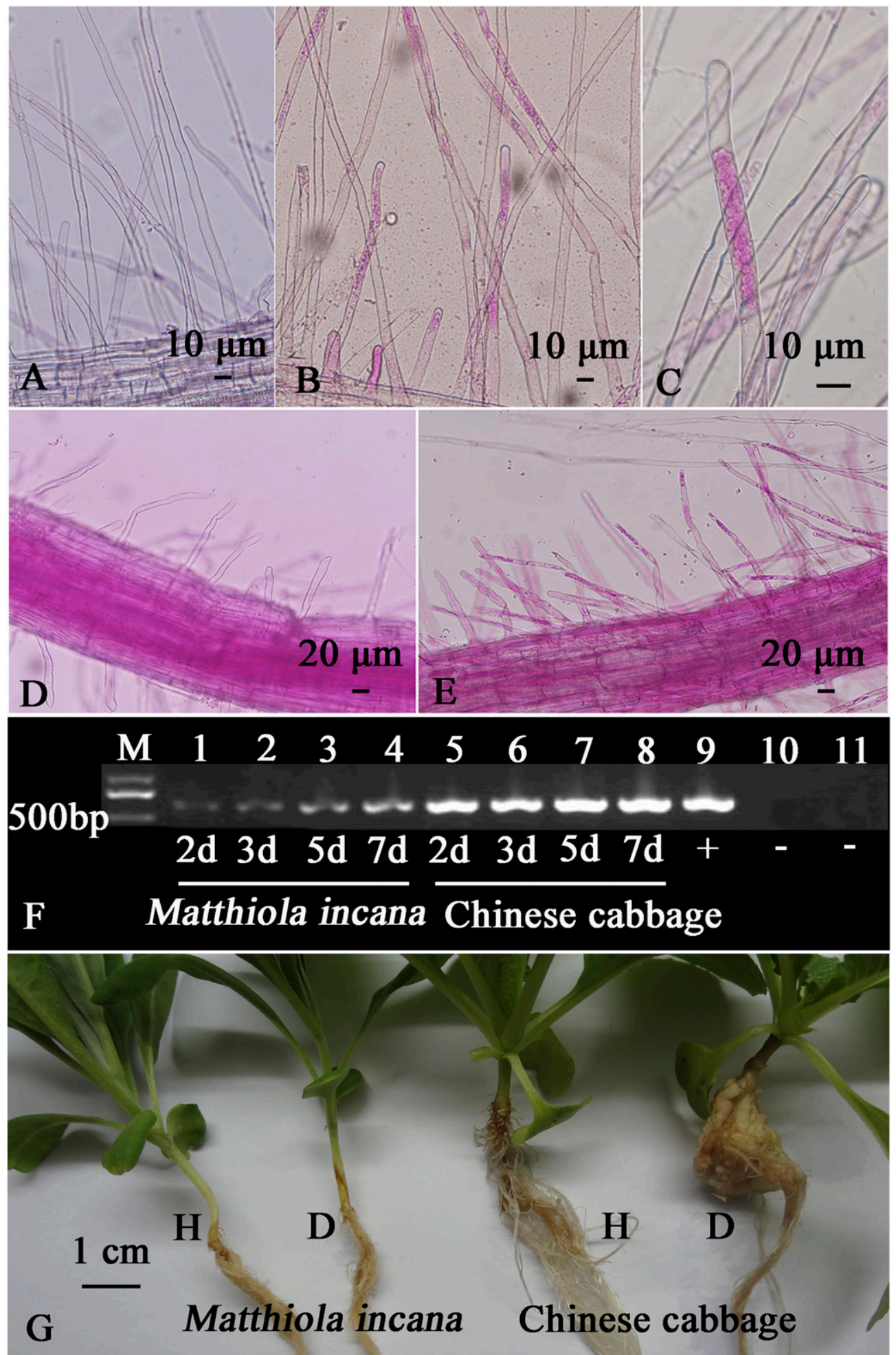

Fig. 2. Infection of Matthiola incana and Chinese cabbage by Plasmodiophora brassicae in liquid culture. A, Healthy root of $M$. incana incubated in Hoagland solution for 7 days (control). B, Root of M. incana with numerous infected root hairs. C, Primary plasmodia in the root hairs of $M$. incana. D, Noninfected root hairs of Chinese cabbage. E, Infected root hairs of Chinese cabbage. F, Molecular detection of $P$. brassicae via polymerase chain reaction. Lane $M=$ marker; lanes 1 to $4=M$. incana at $2,3,5$, and 7 days after inoculation (dai), respectively; lanes 5 to $8=$ Chinese cabbage at $2,3,5$, and 7 dai, respectively; lane $9=$ positive control of galls from Chinese cabbage roots; lane $10=$ negative control of $M$. incana roots from noninfected solution; and lane $11=$ negative control of noninfected $M$. incana roots immersed in $P$. brassicae spore suspension for 10 min and then rinsed with tap water, which was included to make sure that no resting spores were left on the root surface after running water. G, Seedlings of $M$. incana and Chinese cabbage after incubation for 45 days; $\mathrm{H}=$ healthy plants from control solutions and $\mathrm{D}=$ diseased plants from $P$. brassicae-infested solutions. 
slower than in Chinese cabbage, where primary plasmodia could be seen 2 dai. More infected root hairs in $M$. incana and Chinese cabbage were detected at 7 dai, with average infection rates of 32.7 and $67.9 \%$, respectively (Fig. 2B and E). Zoosporangia were also detected in a few root hairs (Fig. 2C). Compared with Chinese cabbage, the infection rate of $M$. incana root hairs was significantly lower $(P<$ 0.05 ) on each observation day following inoculation (Fig. 2B, E, and F). Obvious galls developed on the roots of Chinese cabbage at 45 dai, indicating that the disease developed to the cortical infection stage (Fig. 2G). However, at the end of incubation, no galls were found on the roots of the M. incana.

\section{Discussion}

All members of the family Brassicaceae are potential hosts of P. brassicae (Dixon 2009); however, systematic studies on this subject are lacking. This study demonstrated that $P$. brassicae can infect and sporulate in the roots of 16 genera of crops, ornamentals, and weeds (Table 1); however, M. incana was resistant to the pathogen. Two lines of evidence support this conclusion. First, we randomly selected eight varieties (five from the United States and three from China) of $M$. incana to test resistance. None of these varieties produced galls when grown in naturally infested soil in the field or in inoculated pots; however, the Chinese cabbage plants were severely infected under similar conditions (Table 1). Second, resting spores were observed in the roots of $P$. brassicae-infected Chinese cabbage and I. umbellate via SEM; however, no similar structures were found in the roots of $M$. incana plants (Fig. 1). Despite the fact that specific PCR could detect $P$. brassicae DNA in $M$. incana roots and primary infections were observed in the root hairs, no clubroot symptoms developed on $M$. incana roots in all test conditions.

The clubroot disease cycle consists of two phases, a primary phase in root hairs and a secondary phase in cortical cells which leads to gall formation and yield loss (Kageyama and Asano 2009). Root hair infection occurs prior to the development of visible galls. In this study, $M$. incana did not produce galls; however, root hair infections were observed microscopically. Root hair infection has been reported in resistant (Hwang et al. 2011) and even in nonhost plants, such as papaya and clover (Ludwig-Müller et al. 1999). Differences were reported by Hwang and others (2011) in resistant and susceptible canola, which indicated that the incidence of root hair infection was two- to threefold higher in susceptible than in resistant cultivars. Similar results were obtained in this study. Primary infection in $M$. incana occurred later and the infection rate was significantly lower than in Chinese cabbage. The incidence of root hair infection in $M$. incana roots at 7 dai was $32.7 \%$, compared with $67.9 \%$ for Chinese cabbage.

Cortex infection is the period during which susceptibility or resistance becomes apparent. The secondary phase is reduced or delayed in resistant plants (Diederichsen et al. 2009; Donald et al. 2008; Gludovacz et al. 2014). Because root hair infection causes no yield loss, a crop that has only root hair infection or stimulates resting spore germination could be planted to reduce resting spore populations in heavily infested fields. These plants can serve as bait crops. Various plants such as leafy daikon (R. sativus), red clover (Trifolium pratense), bentgrass (Agrotis palustris), and perennial ryegrass (Lolium perenne), which had similar responses to clubroot (root hair infection only) as $M$. incana, are known to reduce clubroot severity (Ahmed et al. 2011; Murakami et al. 2000). In the current study, no cortical infection was observed in $M$. incana roots, suggesting that $M$. incana can function as a potential bait crop for controlling clubroot. However, more work is required before $M$. incana can be used as a management strategy.

Previously, Liu (2012) reported the occurrence of M. incana clubroot in 2006 in Yunnan Province of China. Such contradictory results could be due to the differences in pathotypes of $P$. brassicae and the different $M$. incana varieties used. Physiological races have long been known to occur in P. brassicae. Numerous sets of differential hosts have been proposed to identify races of $P$. brassicae (Buczacki et al. 1975; Williams 1966), with the Williams differential system being the most commonly used in China. In total, eight races were identified in 12 provinces and municipalities of China using the Williams differentiation system (Ji et al. 2013; Peng et al. 2013; Shen et al. 2009). Race 4 represents $78.5 \%$ of the population characterized in China thus far. Race 4 was also thought to be predominant on cruciferous plants and in the process of spreading the disease throughout China (Chai et al. 2014). Other races, such as $1,2,7,9,10,11$, and 13 , have also been identified with limited occurrence. The physiological race of $P$. brassicae in our sampling sites was pathotype 4 , as determined using the Williams differentiation system (Ji et al. 2013); however, the pathotype of $P$. brassicae in Liu's experiments was not known. Moreover, several pathotypes may occur in one population (Manzanares-Dauleux et al. 2001). Although pathotype 4 was identified in the sampling locations in 2013, the pathotype composition of $P$. brassicae populations may change in response to the selection pressure provided by the cultivars used (Diederichsen et al. 2009). Therefore, in order to determine the host range of a specific pathotype, further studies must use single-spore isolates.

Resistance is the most effective strategy for clubroot management. Over the past decades, many efforts have been made to screen for clubroot resistance, which has been reported in some crops, including Chinese cabbage, field mustard, kale, radish, and oilseed rape (Crisp et al. 1989; Peng et al. 2014; Zhang et al. 2015). Among the 297 accessions of oilseed rape of three Brassica spp., three accessions of $B$. napus and one accession of $B$. juncea were highly resistant to clubroot and these resistant resources provide options for disease management. M. incana was found to be nearly immune to clubroot. Accordingly, the eight $M$. incana varieties used in the current study are good sources of resistance to the predominant $P$. brassicae pathotype in China.

In our study, many cultivars and weeds were highly susceptible to clubroot. Effective management of susceptible cruciferous weeds is important in clubroot management. Susceptible weeds may play an important role in providing $P$. brassicae primary inoculum within the cropping season. C. bursa-pastoris, S. alba, Thellungiella salsuginea, D. sophia, and Lepidium apetalum are common weeds in China that showed obvious root hypertrophy after inoculation with $P$. brassicae. Naturally clubroot-infected C. bursa-pastoris and $S$. alba were also found in the field. These cruciferous weeds may serve as alternative hosts for $P$. brassicae in the absence of susceptible crops and may contribute to the persistence of the pathogen.

The current study confirmed the universal hosts of $P$. brassicae (including Brassica cultivars and radish) and identified an additional 16 host species, including 3 crops (N. officinale, E. sativa and Isatis tinctoria), 8 ornamentals (Lobularia maritima, Cheiranthus cheiri, C. allionii, C. maritimus, H. matronalis, Iberis umbellate, O. violaceus, and Malcolmia maritime), and 5 weeds (Capsella bursa-pastoris, D. sophia, Lepidium apetalum, T. salsuginea, and S. alba). The current study also showed that the cruciferous ornamental Matthiola incana was highly resistant to $P$. brassicae. Primary infection of root hairs occurred in $M$. incana but secondary infection in cortical cells did not occur, resulting in no gall formation. Consequently, $M$. incana has the potential to be developed as a bait crop. This study also highlights the importance of controlling cruciferous weeds for effective management of clubroot.

\section{Acknowledgments}

We thank W. Chen of United States Department of Agriculture-Agricultural Research Service, Washington State University, for language editing.

\section{Literature Cited}

Ahmed, H. U., Hwang, S. F., Strelkov, S. E., Gossen, B. D., Peng, G., Howard, R. J., and Turnbull, G. D. 2011. Assessment of bait crops to reduce inoculum of clubroot (Plasmodiophora brassicae) of canola. Can. J. Plant Sci. 91:545-551.

Buczacki, S. T., and Ockendon, J. G. 1979. Preliminary observations on variation in susceptibility to clubroot among collections of some wild crucifers. Ann. Appl. Biol. 92:113-118.

Buczacki, S. T., Toxopeus, H., Mattusch, P., Johnston, T. D., Dixon, G. R., and Hobolth, L. A. 1975. Study of physiologic specialization in Plasmodiophora brassicae: Proposals for attempted rationalization through an international approach. Trans. Br. Mycol. Soc. 65:295-303. 
Chai, A. L., Xie, X. W., Shi, Y. X., and Li, B. J. 2014. Research status of clubroot (Plasmodiophora brassicae) on cruciferous crops in China. Can. J. Plant Pathol. 36(Suppl.):142-153.

Crisp, P., Crute, I. R., Sutherland, R. A., Angell, S. M., Bloor, K., Burgess, H., and Gordon, P. L. 1989. The exploitation of genetic resources of Brassica oleracea in breeding for resistance to clubroot (Plasmodiophora brassicae). Euphytica 42:215-226.

Diederichsen, E., Frauen, M., Linders, E. G. A., Hatakeyama, K., and Hirai, M. 2009. Status and perspectives of clubroot resistance breeding in Crucifer crops. J. Plant Growth Regul. 28:265-281.

Dixon, G. R. 2009. The occurrence and economic impact of Plasmodiophora brassicae and clubroot disease. J. Plant Growth Regul. 28:194-202.

Donald, E. C., Jaudzems, G., and Porter, I. J. 2008. Pathology of cortical invasion by Plasmodiophora brassicae in clubroot resistant and susceptible Brassica oleracea hosts. Plant Pathol. 57:201-209.

Donald, E. C., and Porter, I. J. 2004. A sand-solution culture technique used to observe the effect of calcium and $\mathrm{pH}$ on root hair and cortical stages of infection by Plasmodiophora brassicae. Australas. Plant Pathol. 33:585-589.

Feng, J., Hwang, S. F., and Strelkov, S. E. 2013. Genetic transformation of the obligate parasite Plasmodiophora brassicae. Phytopathology 103:1052-1057.

Gludovacz, T. V., Deora, A., McDonald, M. R., and Gossen, B. D. 2014. Cortical colonization by Plasmodiophora brassicae in susceptible and resistant cabbage cultivars. Eur. J. Plant Pathol. 140:859-862.

Honig, F. 1931. Der Kohlkropferreger (Plasmodiophora brassicae Wor.). Eine Monographie Die Gartenbauwissenschaft 5:116-225.

Howard, R. J., Strelkov, S. E., and Harding, M. W. 2010. Clubroot of cruciferous crops-New perspectives on an old disease. Can. J. Plant Pathol. 32:43-57.

Hwang, S. F., Ahmed, H. U., Strelkov, S. E., Gossenc, B. D., Peng, G., and Turnbull, G. D. 2011. Influence of cultivar resistance and inoculum density on root hair infection of canola (Brassica napus) by Plasmodiophora brassicae. Plant Pathol. 60:820-829.

Hwang, S. F., Cao, T., Xiao, Q., Ahmed, H. U., Manolii, V. P., Turnbull, G. D., Gossen, B. D., Peng, G., and Strelkov, S. E. 2012. Effects of fungicide, seeding date and seedling age on clubroot severity, seedling emergence and yield of canola. Can. J. Plant Sci. 92:1175-1186.

Ji, H. W., Ren, L., Chen, K. R., Xu, L., Liu, F., Sun, C. C., Li, J., Liu, S. Y., and Fang, X. P. 2013. Identification of physiological races of club root and resistance of rape cultivars to Plasmodiophora brassicae. Chin. J. Oil Crop Sci. 35:301-306. (In Chinese)

Kageyama, K., and Asano, T. 2009. Life cycle of Plasmodiophora brassicae. J. Plant Growth Regul. 28:203-211.

Karling, J. S. 1968. The Plasmodiophorales, 2nd ed. Hafner Publishing Co., New York.

Kim, W. G., Lee, S. Y., Choi, H. W., Hong, S. K., and Lee, Y. K. 2011. Occurrence of clubroot on shepherd's-purse caused by Plasmodiophora brassicae. Mycobiology 39:233-234.

Kuginuki, Y., Hiroaki, Y., and Hirai, M. 1999. Variation in virulence of Plasmodiophora brassicae in Japan tested with clubroot-resistant cultivars of Chinese cabbage (Brassica rapa L. spp. pekinensis). Eur. J. Plant Pathol. 105:327-332.

Liu, W. W. 2012. Control of clubroot on Matthiola incana. Yunnan Agric. 11:20. (In Chinese)
Ludwig-Müller, J., Bennett, R. N., Kiddle, G., Ihmig, S., Ruppel, M., and Hilgenberg, W. 1999. The host range of Plasmodiophora brassicae and its relationship to endogenous glucosinolate content. New Phytol. 141:443-458.

Luo, H. C., Chen, G. K., Liu, C. P., Huang, Y., and Xiao, C. G. 2014. An improved culture solution technique for Plasmodiophora brassicae infection and the dynamic infection in the root hair. Australas. Plant Pathol. 43:53-60.

Manzanares-Dauleux, M. J., Divaret, I., Baron, F., and Thomas, G. 2001 Assessment of biological and molecular variability between and within field isolates of Plasmodiophora brassicae. Plant Pathol. 50:165-173.

Murakami, H., Tsushima, S., Akimoto, T., Murakami, K., Goto, I., and Shishido, Y. 2000. Effects of growing leafy daikon (Raphanus sativus) on populations of Plasmodiophora brassicae (clubroot). Plant Pathol. 49:584-589.

Paz Lima, M. L. P., Café-Filho, A. C., Nogueira, N. L., Rossi, M. L., and Schuta, L. R. 2004. First report of clubroot of Eruca sativa caused by Plasmodiophora brassicae in Brazil. Plant Dis. 88:573.

Peng, G., Falk, K. C., Gugel, R. K., Franke, C., Yu, F., James, B., Strelkov, S. E., Hwang, S. F., and McGregor, L. 2014. Sources of resistance to Plasmodiophora brassicae (clubroot) pathotypes virulent on canola. Can. J. Plant Pathol. 36: 89-99.

Peng, S. S., Ren, Z. H., Huang, X. L., Liu, M. J., Sun, L. F., and Liu, E. M. 2013 Physiological race identification on clubroot of cruciferous crops caused by Plasmodiophora brassicae in Hunan. J. Changjiang Veg. 6:46-49. (In Chinese)

Ren, L., Fang, X. P., Sun, C. C., Chen, K. R., Liu, F., Li, M., and Xu, L. 2014. First report of clubroot on Capsella bursa-pastoris caused by Plasmodiophora brassicae in Sichuan province of China. Plant Dis. 98:687.

Ren, L., Jia, J. G., Li, M., Liu, F., Cheng, Y. G., Zhang, M. H., Chen, K. R., and Fang, X. P. 2012. Distribution of rapeseed clubroot disease in Hubei province and evaluation of yield loss. Agric. Sci. Technol. 13(4):775-777, cover 3.

Shen, X. Q., Nie, K., Wu, Q., Zhang, Y. G., and Meng, X. H. 2009. Initial research report on differentiation identification of Chinese cabbage clubroot main physiological races. Chin Veg. 8:59-62. (In Chinese)

Tanaka, S., Ito, S., Kameya-Iwaki, M., Katumoto, K., and Nishi, Y. 1993. Occurrence and distribution of clubroot disease on two cruciferous weeds, Cardamine flexuosa and C. scutata, in Japan. Trans. Mycol. Soc. Jpn. 34: 381-388.

Tanaka, S., Mizui, Y., Terasaki, H., and Ito, S. 2006. Distribution of clubroot disease of a cruciferous weed, Cardamine flexuosa, in major isolated islands, Hokkaido and Okinawa, in Japan. Mycoscience 47:72-77.

Wang, J., Huang, Y., Li, X. L., and Li, H. Z. 2011. Research progress in clubroot of crucifers. Plant Prot. 37:153-158. (In Chinese)

Williams, P. H. 1966. A system for the determination of races of Plasmodiophora brassicae that infect cabbage and rutabaga. Phytopathology 56:624-626.

Xiong, G. R., Zheng, J. F., Wu, Y. X., and He, Y. Q. 2012. A new disease, clubroot of Isatis tinctoria L. J. Agric. Catastro. 2:3-4. (In Chinese)

Xue, S., Cao, T., Howard, R. J., Hwang, S. F., and Strelkov, S. E. 2008. Isolation and variation in virulence of single-spore isolates of Plasmodiophora brassicae from Canada. Plant Dis. 92:456-462.

Zhang, H., Feng, J., Zhang, S., Zhang, S., Li, F., Strelkov, S. E., Sun, R., and Hwang, S.-F. 2015. Resistance to Plasmodiophora brassicae in Brassica rapa and Brassica juncea genotypes from China. Plant Dis. 99:776-779.

Zhang, Z. M., and Zhao, Y. C. 2012. Identification of new symptoms of radish clubroot. Chin. Plant Prot. 12:44-45. (In Chinese) 